\title{
Arquitetura Italiana Racionalista nos Anos 1930
}

Paulo Bruna

Resumo

Este texto foi originalmente preparado para uma palestra sobre a formação do arquiteto Rino Levi na Itália e apresentado numa mesa redonda organizada por Bruno Giovanetti, no contexto da exposição "Arquitetura Italiana em São Paulo" A palestra procurava mostrar a presença simultânea de duas correntes de pensamento no fim dos anos 1920: do racionalismo centrado sobretudo em Milão e em arquitetos como Persico, Pagano e Terragni; e no conservadorismo centrado sobretudo em Roma, cuja figura mais emblemática foi Marcello Piacentini. As conotações políticas derivadas das diferentes formas de adesão do fascismo fizeram com que esse período fosse sujeito a interpretaçōes confusas e tendenciosas no segundo após-guerra. Estudos recentes, sobretudo norte-americanos, procuram restabelecer os papéis efetivamente desempenhados pelos vários grupos nesse conturbado período.

\footnotetext{
Abstract

This paper was originally prepared for a debate organized by Bruno Giovanetti in the context of the exhibition "Italian Architecture in São Paulo" The purpose was to discuss architect Rino Levi's formative years in Italy in the late twenties when two opposing movements were simultaneously present: the rationalism centred in Milan and powered by such architects as Persico, Pagano and Terragni; and the more conservative approach which had its centre in Rome and in architets such as Marcello Piacentini. After the second world war this period was the subject of very controversial and quite passionate interpretations due to different forms of political association with fascism. Recent studies, manily by American scholars, are reviewing this raged period in order to establish the roles effectively played by these movements and architects.
}

Professor Doutor de História da Arquitetura e de Teoria e História da Urbanização 
Para a geração de arquitetos que se forma em Roma nos anos posteriores à Primeira Guerra, as influências foram múltiplas e complexas, interligadas e não excludentes. Esse aspecto foi enfatizado pelo historiador Dennis P. Doordan quando escreveu: "Um dos mais fascinantes aspectos da história da arquitetura italiana, entre 1914 e 1936, é a procura persistente, pelos arquitetos progressistas, de uma arquitetura capaz de reconciliar os temas de projeto que Persico tão suscintamente sumarizou: as novas formas arquitetônicas e o renascimento do gosto clássico, o prático e o expressivo, o monumental e o utilitário, o singular e o protótipo. Esse programa ambicioso, produziu um volume de trabalhos muito mais variado e sutil que a maioria dos críticos está disposta a reconhecer. A possibilidade de múltiplas leituras de um projeto, mais que prejudicá-lo, de fato vai aumentar a capacidade de uma determinada imagem exprimir diversos fatores, que examinados em conjunto, constituem a trama da história. A prática da arquitetura começa como um trabalho de projeto que envolve uma grande variedade de aspectos estéticos e culturais e termina como um trabalho de construção intimamente relacionado a considerações econômicas e materiais. O estudo da história arquitetônica, portanto, oferece a oportunidade única para avaliar as relações entre as dimensões culturais e econômicas da modernização"

Essa visão múltipla e complexa da cultura italiana no período entre guerras, está sendo reavaliada por uma série de trabalhos recentes, sobretudo estrangeiros². que procuram entender o processo de modernização da arquitetura como uma continuidade entre a tradição e a condição moderna, sem que estas se tornem categorias mutuamente excludentes. Nesse contexto, a tradição não será apenas aquela derivada do classicismo e do barroco, mas também das técnicas e formas artísticas da cultura popular, o que vai conduzir, nos anos da reconstrução à obras como os bairros INA - Casa Tiburtino em Roma (1949-54), Cerignoea em Foggia (1950), Tuscolano em Roma (1950-54) ou à cidade nova de La Martella em Matera $(1951)^{3}$

De uma forma muito simplificada, o processo de modernização seria reapresentado pelo desenvolvimento do racionalismo, em particular pelos quatro artigosmanifestos publicados em 1926 e 1927. na Revista Rassegna Italiana, pelo Gruppo 74; pelas exposições de arquitetura racionalista em 1928 e 1930; pela organização do MIAR Movimento Italiano per l'Architettura Razionale - que iria representar a Itália nos CIAM - Congrès Internationaux d'Architecture Moderne e pelo grupo Quadrante ${ }^{5}$ Milão seria o centro da avant-garde onde Eduardo Persico dirigia a Revista Casabella com Giuseppe Pagano ${ }^{6}$. Roma representaria - bastião do conservadorismo e do tradicionalismo onde a continuidade da arquitetura do século 18 deveria emprestar dignidade ao recém-constituído Reino da Itália. Marcello Piacentini, professor da cadeira de Edilizia, na Real Escola Superior de Arquitetura e influente arquiteto, membro da Revista Architettura e grande polemista, seria sua figura mais notável.

Ainda que fortemente influenciados pelos desenvolvimentos do Movimento Moderno na Alemanha e Holanda e perfeitamente a par dos manifestos mais polêmicos, como o recém-publicado Vers une Architecture de Le Corbusier ${ }^{7}$ os racionalistas do Gruppo 7 eram devedores de seus predecessores italianos. "Dos futuristas, eles herdaram a certeza de que as convençōes do passado eram inadequadas para enfrentar os desafios do presente. Os racionalistas estavam empenhados em criar uma identidade arquitetônica contemporânea. Dos arquitetos do movimento novecento, eles aceitaram a premissa de que o respeito pela tradição e o engajamento na modernidade não precisam ser posições incompatíveis, desde que os arquitetos entendam cada termo 
corretamente" 8 . Os racionalistas identificaram e associaram ao processo de modernização todos os temas que acabaram por predominar nos 15 anos seguintes: as noções de funcionalismo, de racionalização da construção, das tipologias habitacionais, da estética contemporânea, do respeito pela tradição e da responsabilidade individual do arquiteto. Curiosamente, os artigos da Rassegna Italiana não abordam dois temas que se revelariam fundamentais nos anos 30 : o papel do Estado no relacionamento da arquitetura com as ideologias e os efeitos da depressão econômica, que foram acentuados pelo embargo comercial imposto à Itália pela Liga das Nações, após a invasão da Etiópia em $1936^{\circ}$

Para Terragni, cabia ao Estado promover a construção de habitações proletárias, ainda que não concordasse inteiramente com as teses e pressupostos dos $\mathrm{CIAM}^{10}$ Para Piacentini, essas eram elocubrações "nórdicas" Para ele, o problema da casa mínima não era um problema italiano, sendo que ademais, essa preocupação "sufocava" a arquitetura italiana. Terragni entendia que essa posição era excessivamente rígida e que, ao construir habitações proletárias, o Estado estaria atendendo a uma importante necessidade social, sem estar com isso sufocando a arquitetura italiana sob o peso do "internacionalismo" 11

Para alguns historiadores, do imediato pós-guerra como Bruno Zevi, por exemplo, Piacentini era pior que o próprio fascismo ${ }^{12}$. Hoje, suas críticas ao racionalismo parecem muito menos agressivas pois partem das mesmas considerações que os racionalistas apresentavam. Piacentini visitou o Weissenhof Siedlung (1927) e expôs a nudez do Imperador chamando a atenção para o reboque descascado, para os espaços sem uso, para as goteiras dos tetos, para o superaquecimento das salas nos edifícios da avant-garde modernista; ele argumentava de uma forma racional e eminentemente razoável que a arquitetura moderna possuía uma base simbólica, mas não uma técnica. Suas diretrizes, particularmente aquelas destinadas para a arquitetura italiana eram bem alicerçadas num realismo climático:..." Nós (italianos) não podemos aceitar de forma alguma as recentes propostas para paredes inteiramente de vidro e para forros baixos: devemos nos defender de um sol escaldante e do excessivo calor seis meses por ano. Isso significa que devemos continuar a usar materiais naturais e pesados, com dimensões que não podem, por causa de sua natureza, ser diferentes daquelas tradicionais"13 Bruno Zevi identifica na tradição cultural italiana e em particular na filosofia de Benedetto Croce a dificuldade encontrada pela crítica racionalista para atribuir aos requisitos técnicos e funcionais a origem da forma ${ }^{14}$. De fato, num ensaio de 1904, Croce havia escrito:..." devo repetir...que no processo da produção artística os elementos práticos e técnicos nunca participam; o que quer dizer, que a fantasia espontânea reina sem rivais do começo ao fim do processo" 15 . Piacentini propunha uma base essencialmente estética para a arquitetura, relegando as considerações de ordem técnica e funcional para um segundo plano ${ }^{16}$ Entendia que 0 credo funcionalista dos arquitetos racionalistas era simplista e inadequado; que as janelas horizontais, as fachadas de vidro e os tetos planos eram talvez possíveis nos climas frios do norte da Europa, mas inviáveis na Itália, onde o clima mediterrâneo exigia uma série de cuidados, como beirais, cornijas, pedimentos, etc. Os escritos de Piacentini alertam para os perigos da água, que escorre ao longo das fachadas, que penetra pelos vãos das janelas destruindo os revestimentos e, por fim, a construção como um todo. Além disso, Piacentini entendia que existia uma ordem, mais propriamente uma hierarquia, na arquitetura, segundo a qual o que era apropriado para edifícios industriais e comerciais não o era para edifícios religiosos ou institucionais de caráter monumental. "Os racionalistas não haviam 
ainda desenvolvido, na sua opinião, uma fórmula arquitetônica suficientemente rica e sutil para atender toda a gama de expressōes arquitetônicas necessárias numa grande cidade" 17

O tom conciliatório da resposta apresentada pelos arquitetos racionalistas através de um artigo de Adalberto Libera, publicado na Revista Rassegna Italiana de maio/1929, indicava a expectativa dos arquitetos racionalistas de participar das grandes obras que o regime fascista pretendia realizar. Essas relações sempre foram ambíguas e contraditórias, pois, se por um lado a obra prima do racionalismo italiano é a casa del Fascio em Como (1932-1936) de Giuseppe Terragni, este não participou das obras da Universidade de Roma, coordenadas por Marcello Piacentini na mesma data.

A historiografia do após-guerra foi extremamente seletiva em relação aos arquitetos que, formados nas décadas de 20 e 30 exerceram com maturidade e competência a arquitetura da reconstrução ${ }^{18}$ Como passar dos anos, está sendo possivel examinar com isenção esse período e compreender de forma mais adequada a contribuição que os arquitetos italianos dessa geração deram ao desenvolvimento da arquitetura brasileira moderna.

\section{Notas}

(1) DOORDAN, Dennis P. Building modern Italy-italian architecture 1914-1936. New York: Princeton Architectural Press, 1988.

(2) Ver entre outros os seguintes trabalhos:

SCHUMACHER, Thomas L. Surface \& Symbol - Giuseppe Terragniand the architecture of Italian rationalism. New York: Princeton Architectural Press, 1991.

GHIRARDO, Diane Y. Italian architects and fascist politics: An evaluation of the rationalist's role in regime building. Journal of the Society of Architectural Historians, v. 39, may 1980, p. 109-127.

SHAPIRO, Ellen. The Emergence of Italian Rationalism. In: Architectural Design, n. 51, p. 8, jan./feb. 1981.

Esta pesquisadora americana traduziu e publicou todos os artigos iniciais do Gruppo 7:

SHAPIRO, Ellen. Gruppo 7, Architecture (1926), and Architecture II: The Foreigners (1927). In: Oppositions, n. 6, p. 86-102; fall 1976, Gruppo 7, Architecture III: Unpreparedness-Incomprehension-Prejudice (1927), and Architecture IV: A New Archaic Era (1927). In: Oppositions, n. 12, p. 88-104, (Spring 1978).

(3) BRUNETTI, Fabrizio. L'Architettura in Italia negli anni della Ricostruzione. Firenze: Alinea Editrice, 1986.

(4) Os artigos iniciais foram publicados por sete jovens arquitetos formados no Politécnico de Milāo: Ubaldo Castagnoli (substituldo por Adalberto Libera em 1927), Luigi Figini, Guido Frette, Sebastiano Larco, Gino Pollini, Carlo Enrico Rava e Giuseppe Terragni. Por educaçāo, temperamento e consciência politica eles claramente eram o produto das condições econômicas, sociais e politicas do após-guerra.

(5) A Revista Quadrante publicada em Roma por Massimo Bontempelli e P. M. Bardi reuniu um seleto grupo de arquitetos e artistas, alguns da regiāo de Como.

O último número, publicado em 1936, era uma monografia sobre a "Casa del Fascio" em Como, projeto de G. Terragni, cuja amizade com P. M. Bardi durou toda sua vida.

(6) A Revista Casabella, com o subtítulo "Continuità". foi dirigida no após-guerra (a partir de janeiro 1954) pelo arquiteto Ernesto N. Rogers, que a transformou na melhor e mais polêmica publicação da Itália. Saíram de suas páginas os mais influentes artigos, e críticos como Aldo Rossi. Ver: Rogers, Ernesto N. Esperienza dell'architettura: Torino: Giulio Einaudi editore, 1958.

(7) No primeiro artigo-manifesto do Gruppo 7, publicado em dezembro de 1926, lia-se..."É opinião corrente que no campo das artes nosso tempo caracteriza-se pela confusāo e pela desordem. Assim era, e talvez assim era até recentemente, mas hoje certamente não é o caso. Atravessamos um período de formaçāo, que agora amadureceu e foi o trabalho deste periodo de formação, que causou um sentimento geral de desorientação (talvez mesmo os homens dos primeiros anos do século 15 se sentissem desorientados: a comparação não é excessiva, uma vez que estamos verdadeiramente no umbral de um grande perlodol. Um “novo esplrito" nasceu". Este apelo retórico ao "spirito nuovo" lembra o uso do lema "L'esprit Nouveau" no pavilhão apresentado por Le Corbusier na Exposição de Artes Decorativas de Paris em 1925.

(8) DOORDAN, Dennis P., Ibidem, p. 51. 
(9) Em termos de arquitetura, o embargo comercial implicou a súbita escassez de aço e outros materiais de construção. A resposta de Mussolini foi a criação da "autarchia", isto é a auto-sufuciência da Itália. "Os arquitetos imedia tamente assumiram o desafio de criar um sistema autárquico de construção, alguns retornando a formas mais tradicionais de construção; outros, como Terragni, procurando caminhos que lhe permitissem prosseguir no modernismo sem armaduras de aço. Se a autarquia mudou a direção da arquitetura italiana é imposslvel julgar, uma vez que os edifícios erigidos antes de 1936 eram diferentes daqueles erigidos no norte da Europa e aqueles construldos ap6s foram influenciados por muitos outros fatores". Schumacher, Thomas L. Ibidem, p. 31.

(10) Alberto Sartoris foi o único representante italiano em La Sarraz. Em outubro de 1929, ele e Carlo Enrico Rava assistiram ao segundo congresso CIAM em Frankfurt. Ao retornar, deram inicio a uma organizaçāo de arquitetos progressistas tentativamente denominada MAR-Movimento Architettura Razionale. Ver: Fagiolo Marco. Alle origini del razionalismo italiano. In: Ottagono, n. 35, dez. 1974.

(11) MANTERO, Enrico. Giuseppe Terragni e la Città del razionalismo in Italia. Roma: Dedalo, 1969, p.102-104.

(12) Veja-se por exemplo: "Uma análise tranquila leva à conclusão que o Movimento Racionalista Italiano, diferentemente dos desenvolvimentos na Alemanha Nazista ou na União Soviética, não foi sufocado pelo Partido Fascista, mas por uma doença muito mais antiga e mais crônica, doença que infeccionou o próprio fascismo... mau hábito do transformismo. Em arquitetura, seu principal expoente foi Marcello Piacentini" Bruno Zevi. Gruppo 7 and the Rise and Fall of Italian Rationalism. In: Architectural Design, n. 51, jan. 1981 , p. 42.

(13) PIACENTINI, Marcello. L'Architettura Oggi, Roma: Paolo Cremonese, 1930, citado por SCHUMACHER, Thomas, Ibidem, p. 28.

(14) ZEVI, Bruno. Storia dell'architettura moderna. Torino: Giulio Einaudi, 1950, p. 211

(15) CROCE, Benedetto. II padroneggiamento della tecnica. (1904) In: La Critica e la storia delle arti figurative: Questioni di metodo. Bari: 1934, p. 94-95, citado por Doordan, Dennis, ibidem, p.73.

(16) ..."Porque associam eles (os racionalistas) os dois termos: arquitetura e racionalidade?...Em resumo, a identificação do belo com a estrutura não existe. Deixemos estas especulaçōes áridas e metafísicas aos homens do Norte. Nem o puritanismo nem o protestantismo jamais criaram ralzes sob nosso sol. Necessitamos do gesto e da forma, a bela palavra e o sorriso. Somos basicamente musicais, a arte para nós é uma cançāo" - Piacentini Marcello. Prima internazionale architettonica. In: Architettura e Arti Decorative, n. 7. Roma, ago. 1928.

(17) PIACENTINI, Marcello. - Problemi reali più che razionalismo preconcetto. In: Architettura e Arti Decorative, $n$. 10. Roma, nov. 1928, citado por Dennis Doordan, Ibidem, p.73.

(18) VERONESI, Giulia. Difficoltà politiche dell'architettura in Italia, 1920-1940. Milano: Tamburini, 1953, p.62. 